\title{
What lies beneath a facial nerve palsy? Case report of a facial palsy caused by non-suppurative parotitis
}

\author{
Emily Lowe, Carter Singh, Surinder Birdi \\ Department of Ear, Nose and Throat Surgery, Sherwood Forest Hospitals Foundation Trust, United Kingdom
}

Received: June 1, 2016

Accepted: July 18, 2016

Online Published: July 26, 2016

DOI: $10.5430 /$ css.v2n4p17

URL: http://dx.doi.org/10.5430/css.v2n4p17

\begin{abstract}
Objective: Facial nerve palsy is a common presentation with a variety of causes. We present a relatively uncommon cause. Case presentation: A 54-year-old gentleman presented with a left lower motor neurone facial weakness and an associated ipsilateral large firm, non-tender parotid. An ultrasound was in keeping with parotid sialadenitis without abscess formation. He was treated with oral antibiotics and the left parotid swelling and facial palsy improved.

Discussion: Epidemiology dictates that a facial palsy with an associated parotid mass should always be investigated for underlying malignancy, as this remains a more likely presentation. There have been occasional case reports in the literature of this presentation being due to a benign process, such as a parotid abscess. Occasionally, as in this case, the cause may be a non-suppurative parotitis. Infective causes of facial nerve palsy have a good prognosis with likely resolution of the facial palsy.
\end{abstract}

Key Words: Parotitis, Facial paralysis

\section{INTRODUCTION}

Facial nerve palsy is a common presentation with a variety of causes; an upper motor neurone palsy, with forehead sparing, indicates a central cause whereas a lower motor neurone picture could fall under the remit of the otolaryngologist. A facial paralysis with an associated parotid mass is more likely to herald an underlying malignant pathology and the patient should have appropriate investigations to rule out such a diagnosis. However, there have been reports of benign parotid swellings causing a facial palsy, including 25 case reports with an infective aitiology. The majority of these cases have reported a parotid gland abscess causing a facial palsy, with relatively fewer declaring a non-suppurative parotitis as a cause. To our knowledge, this is only the 11th report in the literature of a non-suppurative parotitis presenting with a parotid mass and associated facial palsy since 1972. It is an uncommon cause of a facial palsy but should be considered whilst managing a patient with a facial paralysis. Here we review the literature alongside a case report of facial palsy caused by non-suppurative parotitis.

\section{METHODS}

We present a case report of facial nerve palsy secondary to a non-suppurative parotitis. The literature was searched for any previous such cases to identify the common natural history and likely prognosis of the facial nerve palsy. A Medline and EMBASE database search was conducted using the keywords "parotitis" and "facial paralysis". The search returned 66 journal articles in the English language from 1962 to 2015, the abstracts of which were reviewed to find 20 appropriate articles detailing similar case reports to ours. The references cited were also reviewed to ensure any further case reports

\footnotetext{
*Correspondence: Emily Lowe; Email: emily.lowe@doctors.org.uk; Address: Department of Ear, Nose and Throat Surgery, Sherwood Forest Hospitals Foundation Trust, United Kingdom.
}

Published by Sciedu Press 
were found.

\section{Case presentation}

A 54-year-old gentleman presented to the ENT emergency clinic with a 2-week history of left sided facial palsy. On examination there was a complete lower motor neuron facial weakness. His facial palsy was scored at House-Brackmann $\mathrm{V}$ and he demonstrated Bells' phenomenon (see Figure 1). There was an associated firm, non-tender ipsilateral parotid swelling which had increased in size over the preceding 5 days. Clear saliva could be drained from the parotid duct. He felt systemically well and his observations were within normal range with no evidence of pyrexia. He had no significant past medical history although he had poor oral hygiene. He did not take any regular medications and had an allergy to penicillin.

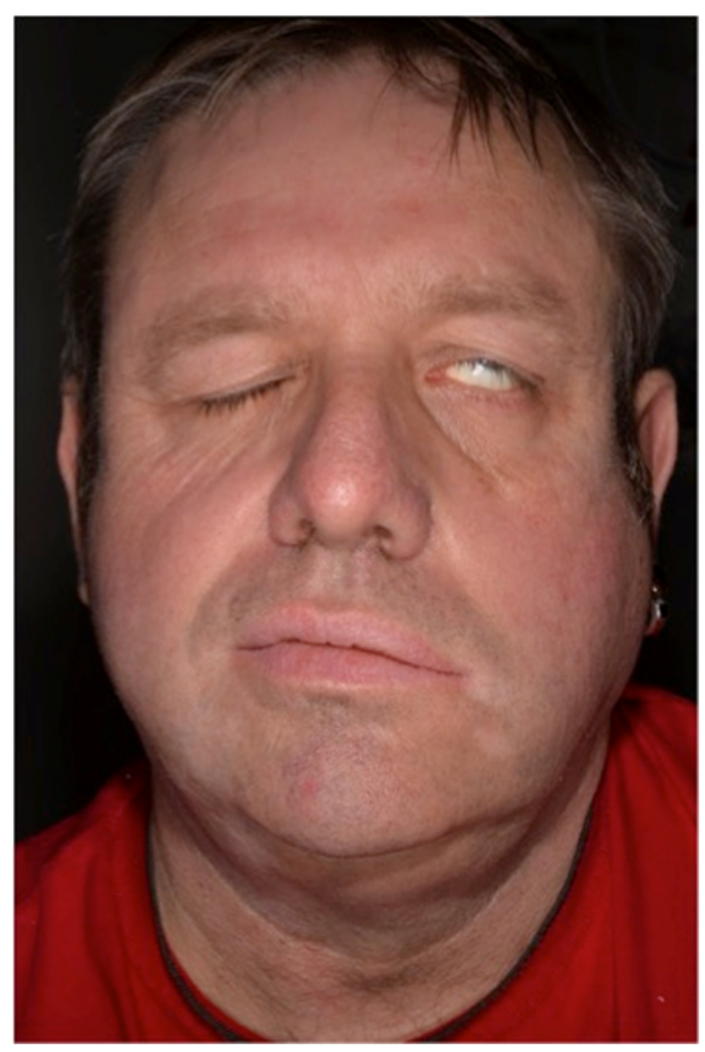

Figure 1. Left facial palsy and parotid swelling, 5 days into treatment

Initial bloods were taken and his inflammatory markers were slightly raised; white cell count $13.1 \times 10^{9} / \mathrm{L}$, neutrophils $10.9 \times 10^{9} / \mathrm{L}$, c-reactive protein $17 \mathrm{mg} / \mathrm{L}$. Due to the acute nature of the presentation and raised inflammatory markers, he was started on empirical oral antibiotics to target oral gram positive and gram negative bacteria, including anaerobes (cefalexin and metronidazole). Despite a reported penicillin allergy, he had no cross-allergy reaction with cefalexin. He was also prescribed an ocular lubricant and advised to use tape for eye care. An ultrasound of his left parotid was conducted (see Figure 2). The parotid was enlarged with a globally course echotexture and a few hypoechoic foci in keeping with sialadenitis. There was no evidence of a parotid mass, ductal calculus or cervical lymph nodes on ultrasound. The patient continued his treatment with oral antibiotics for a total of 10 days and the left parotid swelling improved. At 2 weeks follow-up he had some residual facial nerve palsy, although the parotid swelling had completely settled. Follow-up at 18 weeks (see Figure 3) reveals only mild residual deficit, which is near completely resolved.

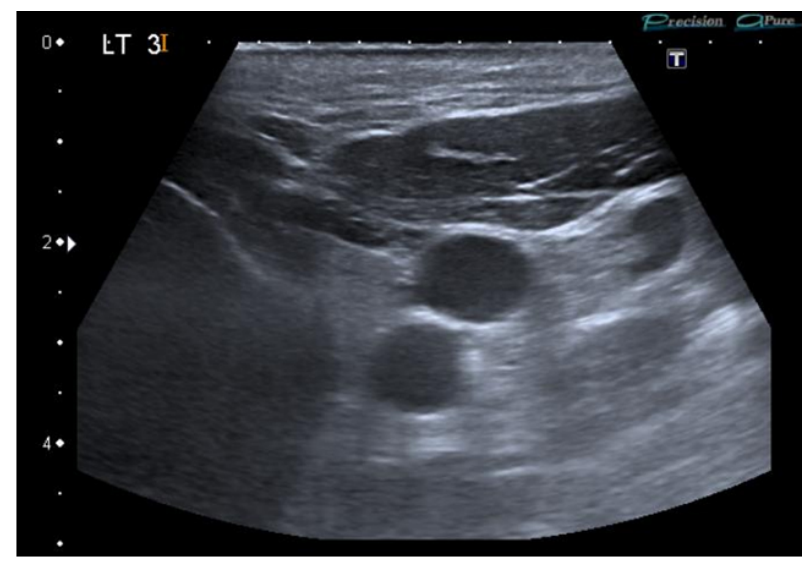

Figure 2. Left parotid ultrasound showing hypoechoic foci

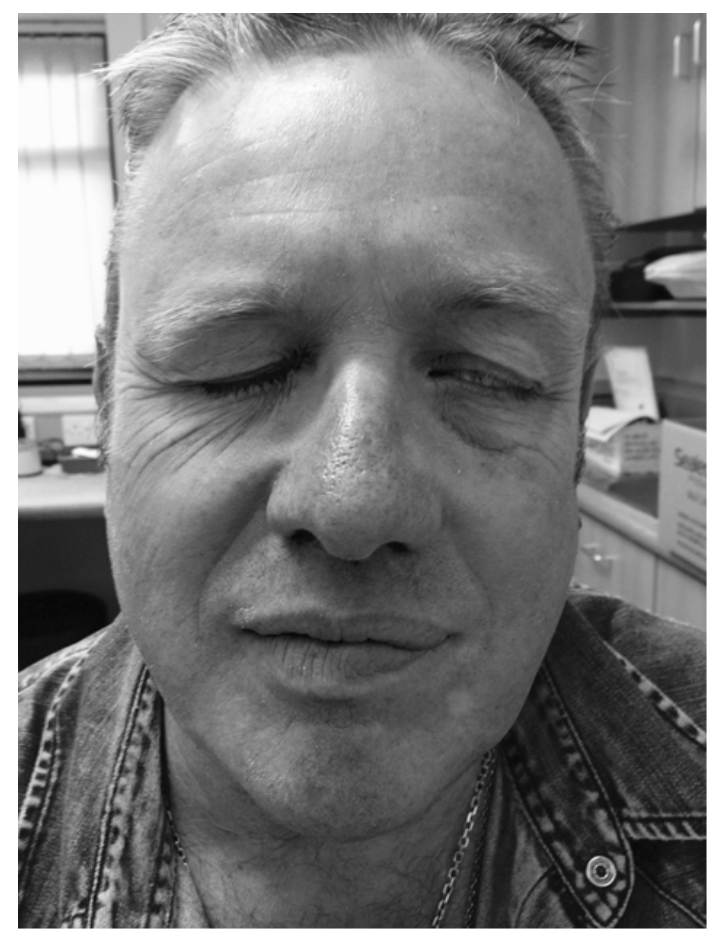

Figure 3. Follow-up 18 weeks after initial presentation 


\section{Discussion}

This case report highlights that a facial palsy with a parotid mass may be due to a benign condition. A review of the literature identified 15 case reports of parotid abscess and 10 of parotitis without abscess causing facial palsy with the earliest reported case in $1972^{[1-20]}$ (see Table 1). Once thought to be a rare presentation, it has now been established in the literature that infectious parotid disease is an uncommon, but possibly under-reported, cause of facial palsy.

Table 1. Results of literature review

\begin{tabular}{|c|c|c|}
\hline Paper & Pathology & Organism \\
\hline Kanzhuly et al. (2014) ${ }^{[1]}$ & Parotid abscess & Klebsiella pneumoniae \\
\hline Hajiioannou et al. (2013) ${ }^{[2]}$ & Parotid abscess & \\
\hline Kristensen et al. (2012) ${ }^{[3]}$ & Parotid abscess (2 cases) & Methicillin-resistant Stapholococcus aureus, Propionibacterium acnes \\
\hline Athar et al. (2009) ${ }^{[4]}$ & Parotid abscess & Klebsiella pneumoniae \\
\hline Noorizan et al. (2009) ${ }^{[5]}$ & Parotid abscess & \\
\hline Incecik et al. (2009) ${ }^{[6]}$ & Parotitis (2 cases) & Paromyxo virus ( 2 cases) \\
\hline Orhan et al. (2008) ${ }^{[7]}$ & Parotid abscess & \\
\hline Makeham et al. (2007) ${ }^{[8]}$ & Parotid abscess & \\
\hline Marioni et al. (2003) ${ }^{[9]}$ & Parotid abscess & Candida albicans \\
\hline Endo et al. (2001) ${ }^{[10]}$ & Parotitis & Paromyxo virus \\
\hline Martinon-Torres et al. (1999) ${ }^{[11]}$ & Parotitis & Parvovirus B19 \\
\hline Smith et al. (1997) ${ }^{[12]}$ & Parotid abscess & Staphlococcus aureus \\
\hline Pang et al. (1996) ${ }^{[13]}$ & Parotid abscess & Staphlococcus aureus \\
\hline Johnson et al. (1991) ${ }^{[14]}$ & Parotitis & Epstein-Barr virus \\
\hline Dance et al. (1989) ${ }^{[15]}$ & Parotid abscess (2 cases) & Pseudomonas pseudomallei (2 cases) \\
\hline Andrews et al. (1989) ${ }^{[16]}$ & $\begin{array}{l}\text { Parotitis ( } 2 \text { cases) } \\
\text { Parotid abscess }\end{array}$ & \\
\hline Robertson et al. (1987) ${ }^{[17]}$ & Parotitis & \\
\hline Shone et al. (1985) ${ }^{[18]}$ & Parotitis & Staphlococcus aureus \\
\hline Andersson et al. $(1985)^{[19]}$ & Parotitis & Epstein-Barr virus \\
\hline Duff $(1972)^{[20]}$ & Parotid abscess & Proteus \\
\hline
\end{tabular}

Commensal organisms, precipitated by dehydration, poor oral hygiene and ductal obstruction from calculi, can cause parotitis. Amongst the published case reports, identified bacterial pathogens included staphlococcus aureus, klebsiella pneumonia, propionibacterium acnes, pseudomonas pseudomellei, proteus, and even candida albicans. There have been at least 3 cases of a facial palsy developing after mumps parotitis in children, 2 cases of mononucleosis parotitis and a case of parvovirus B19 parotitis. Unfortunately we were unable to ascertain any specimens to culture a causative organism in our case.

The explanation for the facial nerve palsy in benign cases is not fully understood. In malignant parotid swellings the tumour can infiltrate the facial nerve. Previous authors have suggested benign swellings affect the facial nerve by compression from direct pressure or damage by a toxic perineuritis. The case report by Shone et al. in 1985, is to date the only author to be able to describe the post-mortem appearance of their patient's parotid gland, as they unfortunately died from an unrelated condition five weeks after presenting with a parotid abscess and facial nerve palsy. They described a local inflammatory process and fibrosis within the parotid gland but no damage to the nerves themselves, supporting the argument of the effects of local compression.

Investigation of facial nerve palsy should begin with a full history and examination. Patients who present with a lower motor neurone facial palsy should have their parotid glands carefully examined so as not to miss an occult abscess or inflammation that can be treated with antibiotics, rather than being mislabelled as a Bell's palsy. The presence of a parotid mass requires further investigation with imaging. Ultrasound is useful to identify a parotid abscess, mass or calculi. Unfortunately it is not always able to identify lesions of the deep parotid gland and CT or MRI may be more helpful.

Regarding management of parotitis, appropriate antibiotics 
to cover gram positive, gram negative and anaerobic organisms should be commenced and any abscess drained either radiologically or surgically. Good oral hygiene and adequate hydration aid in reducing inflammation of the salivary glands. Sialogogues such as lemon juice can also be used. Facial paralysis due to a parotid abscess or parotitis has a good prognosis, with the majority of cases reported in the literature achieving complete resolution within 6 months, after treatment of the infection.

Aside from infective causes, other benign parotid causes of facial palsy that have been reported. Granulomatous disease has been described to present with parotid swelling and facial palsy since $1965 .{ }^{[21]}$ There have been case reports of the rare Heerfordt's syndrome, a form of sarcoidosis with neurological manifestations, presenting with parotid swelling, facial palsy and uveitis. ${ }^{[22,23]}$ Wegener's granulomatosis rarely presents with a parotitis and may cause a facial palsy due to middle ear disease. ${ }^{[24]}$ Benign tumours of the parotid gland can develop surrounding inflammatory changes and lead to a facial palsy, and this process has been described in parotid cystoadenolymphoma, ${ }^{[25]}$ Warthin's tumour, pleo- morphic adenoma, and oncocytoma. ${ }^{[26]}$ This reinforces the idea that when diagnostic doubt exists, these patients should be investigated for an underlying neoplasm.

\section{Conclusion}

We present an uncommon case of parotid sialadenitis without abscess formation presenting with a facial nerve paralysis. Epidemiology dictates that a facial palsy with an associated parotid mass should always be investigated for underlying malignancy, as this remains a more likely presentation. Occasionally, facial nerve palsy can be caused by a benign parotitis. Infective causes of facial nerve palsy have a good prognosis, with likely resolution of the facial palsy once the infection has been treated.

\section{ACKNOWLEDGEMENTS}

We would like to thank the patient for his informed consent for publication, including the use of clinical photographs.

\section{CONFlicts OF INTEREST Disclosure}

The authors declare that they have no competing interests.

\section{REFERENCES}

[1] Kanzhuly M, Gupta D, Muralidharan C. A rare case of suppurative parotitis with facial nerve palsy. International Journal of Otolaryngology, Head and Neck Surgery. 2014; 3: 248-251. http: //dx.doi.org/10.4236/ijohns.2014.35045

[2] Hajiioannou JK, Florou V, Kousoulis P, et al. Reversible facial nerve palsy due to parotid abscess. International Journal of Surgery Case Reports. 2013; 4(11): 1021-1024. PMid: 24096025. http: //dx.doi.org/10.1016/j.ijscr.2013.08.016

[3] Kristensen R, Hahn C. Facial nerve palsy caused by parotid gland abscess. The Journal of Laryngology and Otology. 2012; 126: 322-324. PMid: 22017803. http://dx.doi.org/10.1017/S0022215111 002635

[4] Athar P, Yahya Z, Mat Baki M, et al. Facial nerve paralysis: A rare complication of parotid abscess. Malaysian Journal of Medical Sciences. 2009; 16(2): 38-39.

[5] Athar P, Yahya Z, Mat BM, et al. Facial nerve paralysis: A rare complication of parotid abscess. Malaysian Journal of Medical Sciences. 2009; 16(2): 38-39.

[6] Incecik F, Herguner M, Altunbasak S. Facial palsy caused by mumps parotitis. Neurology India. 2009; 57(4): 511-512. PMid: 19770567 http://dx.doi.org/10.4103/0028-3886.55589

[7] Orhan KS, Deirel T, Kocasoy-Orhan E, et al. Facial paralysis due to an occult parotid abscess. Kulak Burun Bogaz Ihtisas Dergidi. 2008; 18(2): 115-117. PMid: 18628648.

[8] Makeham TP, Croxson GR, Coulson S. Infective causes of facial nerve paralysis. Otology and Neurology. 2007; 28(1): 100-103. http: //dx.doi.org/10.1097/01.mao.0000232009.01116.3f

[9] Marioni G, Rinaldi R, De Fillipis C, et al. Candidal abscess of the parotid gland associated with facial nerve paralysis. Acta Otolaryn- gologica. 2003; 123: 661-663. http://dx.doi.org/10.1080/0 0016480310000449

[10] Endo A, Izumi H, Miyashita M, et al. Facial palsy associated with mumps parotitis. Pediatric Infectious Disease Journal. 2001; 20(8): 815-816. PMid: 11734752. http://dx.doi.org/10.1097/000 06454-200108000-00023

[11] Martinon-Torres F, Seara MJ, Del RPI, et al. Parvovirus B19 infection complicated by peripheral facial palsy and parotitis with intraparotid lymphadenitis. Pediatric Infectious Disease Journal. 1999; 18(3): 307-308. http://dx.doi.org/10.1097/00006454-199 903000-00025

[12] Smith DR, Hartig GK. Complete facial paralysis as a result of parotid abscess. Otolaryngology - Head and Neck Surgery. 1997; 117(6): S114-S117. http://dx.doi.org/10.1016/S0194-599 8 (97) 70075-5

[13] Pang YT, Raine CH. Acute suppurative parotitis and facial paralysis. Journal of Laryngology and Otology. 1996; 110(1): 91-92. http://dx.doi.org/10.1017/S0022215100132815

[14] Johnson PA, Avery C. Infectious mononeucleosis presenting as a parotid mass with associated facial nerve palsy. International Journal of Oral and Maxillofacial Surgery. 1991; 20(4): 193-195. http://dx.doi.org/10.1016/S0901-5027(05) 80171-7

[15] Dance DA, Davis TM, Wattanagoon Y, et al. Acute suppurative parotitis caused by Pseudomonas psuedomallei in children. Journal of Infectious Diseases. 1989; 159(4): 654-660. http://dx.doi.o $\mathrm{rg} / 10.1093 /$ infdis/159.4.654

[16] Andrews JC, Abemayor E, Alessi DM, et al. Parotitis and facial nerve dysfunction. Archives of Otolaryngology - Head \& Neck Surgery. 1989; 115(2): 240-242. http://dx.doi.org/10.1001/archoto 1.1989 .01860260114026 
[17] Robertson JF, Azmy AA. Facial paralysis in acute parotitis. European Journal for Peadiatric Surgery. 1987; 42(5): 312.

[18] Shone GR, Stewart F. Facial paralysis in parotitis. British Journal of Surgery. 1985; 72(11): 902. PMid: 4063762. http://dx.doi.org /10.1002/bjs. 1800721118

[19] Andersson J, Sterner G. A 16-month-old boy with infectious mononeucleosis, parotitis and Bell's palsy. Acta Paediatrics Scandinavica. 1985; 74(4): 629-632. PMid: 2992226. http://dx.doi.o rg/10.1111/j.1651-2227.1985.tb11048.x

[20] Duff T. Parotitis, parotid abscess and facial palsy. The Journal of Laryngology and Otology. 1972; 86(2): 161- 165. http://dx.doi . org/10.1017/S0022215100075095

[21] Richards SH. Parotitis and facial paralysis in mid-line granuloma. The Laryngoscope. 1965; 75(1): 137-143. PMid: 14256342. http: //dx.doi.org/10.1288/00005537-196501000-00015

[22] Arikan FI, Ozkan F, Isik Atras P, et al. Heerfordt's syndrome in an adolescent boy. Archives of Diseases in Childhood. 2012;
97: A149. http://dx.doi.org/10.1136/archdischild-201 2-302724.0513

[23] Magliocca KR, Leung EM, Desmond JS. Parotid swelling and facial nerve palsy: an uncommon presentation of sarcoidosis. General Dentistry. 2009; 57(2): 180-182. PMid: 19552369.

[24] Rajiv KR, Balaji G, Nagabushan MV, et al. Bilateral-otitis media, dacroadenitis, parotitis and left sided infranuclear facial palsy: unusual manifestations of Wegener's granulomatosis. Journal of the Association of Physicians of India. 2013; 61(12): 922-5. PMid: 24968554.

[25] Mantsopoulos K, Psychogios G, Agaimy A, et al. Inflamed benign tumors of the parotid gland: diagnostic pitfalls from a potentially misleading entity. Head \& Neck. 2015; 37(1): 23-9. PMid: 24488708. http://dx.doi.org/10.1002/hed. 23541

[26] O’Dwyer TP, Gullane PJ, Dardick I. A pseudo-malignant Warthin's tumor presenting with facial nerve paralysis. The Journal of Otolaryngology. 1990; 19(5): 353-357. PMid: 2262958. 